\title{
Novel Coronavirus-Induced NLRP3 Inflammasome Activation: A Potential Drug Target in the Treatment of COVID-19
}

\author{
Adnan Shah* \\ University of Ulm, Ulm, Germany
}

Keywords: NLRP3 inflammasome, viroporins, cytokines, SARS-CoV, COVID-19

Novel coronaviruses (nCoVs) encode ion-channel proteins called viroporins such as protein E, open reading frame $3 \mathrm{a}$ (ORF3a) and ORF8a. These viroporins, via mechanisms such as lysosomal disruption and ion-redistribution in the intracellular environment, activate the innate immune signaling receptor NLRP3 (NOD-, LRR-, and pyrin domain-containing 3) inflammasome. This

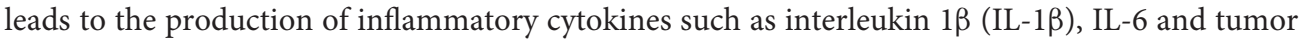
necrosis factor (TNF), causing tissue inflammation during respiratory illness caused by $\mathrm{CoV}$ infection. Due to this crucial role in triggering inflammatory response to infection, the NLRP3 inflammasome appears to be a potential drug target in the treatment of coronavirus disease 2019 (COVID-19), caused by SARS-CoV-2. This manuscript highlights the importance of NLRP3 inflammasome in the pathogenesis of $\mathrm{nCoVs}$, discusses its known inhibitors and draws attention

OPEN ACCESS

Edited by:

Yasuko Tsunetsugu Yokota,

Tokyo University of Technology, Japan

Reviewed by:

Takeshi lchinohe,

University of Tokyo, Japan

*Correspondence:

Adnan Shah

adnan.shah@alumni.uni-ulm.de

Specialty section This article was submitted to

Viral Immunology,

a section of the journal

Frontiers in Immunology

Received: 17 April 2020 Accepted: 28 April 2020

Published: 19 May 2020

Citation:

Shah A (2020) Novel Coronavirus-Induced NLRP3

Inflammasome Activation: A Potential

Drug Target in the Treatment of

COVID-19. Front. Immunol. 11:1021.

doi: 10.3389/fimmu.2020.01021 toward evaluation of these and similar known or novel agents for potential beneficial effects in the treatment of SARS-CoV-2 (COVID-19).

The twenty-first century has witnessed the emergence of three novel coronaviruses (nCoVs): The first outbreak was caused by severe and acute respiratory syndrome coronavirus (SARS-CoV) that emerged in Southeast China in 2002, followed by the Middle East respiratory syndrome-related coronavirus (MERS-CoV) in 2012 (1). The recent pandemic which is caused by SARS-CoV-2 originated at Wuhan city in China in late 2019, is causing a respiratory illness named as coronavirus disease 2019 (COVID-19) which is causing morbidity and mortality worldwide (2).

CoVs carry a positive-sense, single-stranded RNA genome of about $30 \mathrm{~kb}$ and the virion nucleocapsid is surrounded by an envelop which is studded with spike (S), membrane (M), and envelop (E) proteins $(3,4)$. The spike $(S)$ glycoprotein recognizes and interacts with its target called angiotensin converting enzyme 2 (ACE2) receptor on the host cell surface, mediating viral entry during the infection cycle (5). Identifying and exploiting promising therapeutic targets has always been an area of intensive research in the treatment of viral diseases. In this respect, the spike protein of SARS-CoV is also viewed as a drug target due to its role in a crucial checkpoint of viral infection, i.e., viral attachment and entry in to the host cell. Nevertheless, there are also other virus-host interaction mechanisms (see below) that offer attractive targets for potential therapies in the context of infections caused by SARS-CoVs.

\section{ROLE OF NLRP3 INFLAMMASOME IN NOVEL CORONAVIRUS PATHOGENESIS}

Like other animal viruses, SARS-CoV also encode three ion-channel (IC) proteins called viroporins, namely the protein $\mathrm{E}$, open reading frame $3 \mathrm{a}(\mathrm{ORF} 3 \mathrm{a})$ and ORF8a. It has been observed that during the course of viral infections, these viroporins oligomerize and form pores, that disrupt normal 
physiological homeostasis in the host cell and thus contribute to the viral pathogenicity $(4,6,7)$. In SARS-CoV, two of the viroporins, i.e., the more dominant protein $\mathrm{E}$ and also ORF3a, each carrying a PDZ-binding motif (PBM, which interacts with cellular proteins) and also having IC activity, were reported to be required for optimal viral replication. Of these, the protein $\mathrm{E}$ was shown to be necessary for viral virulence (8). Moreover, E protein was shown to be essential, as its absence led to the attenuation of SARS-CoV. In fact, E protein is involved in several signaling mechanisms that ultimately results in inflammation during infection. In addition to its role in activation of the inflammatory NF-kB pathway and interaction of its PBM with syntenin proteins which trigger activation of the p38 MAPK $(9,10)$ it also forms a calcium ion $\left(\mathrm{Ca}^{2+}\right)$ channel in the Endoplasmic Reticulum Golgi Apparatus Intermediate Compartment (ERGIC)/Golgi membranes. As a result of this, changes in calcium homeostasis in the intracellular environment leads to activation of the cytosolic innate immune signaling receptor NLRP3 (NOD-, LRR-, and pyrin domain-containing 3) inflammasome (10), shown in Figure 1. The NLRP3 is composed of adapter component apoptosis-associated speck-like protein carrying a caspase activation and recruitment domain (ASC) and the catalytically inactive procaspase-1 $(11,12)$. It has been shown that several external and internal stimuli including viral RNA, activate the NLRP3 inflammasome via mechanisms such as formation of pores with ion-redistribution and lysosomal disruption, resulting in inflammation and associated cell death called pyroptosis (13). Upon activation of the NLRP3, its procaspase-1 is converted into the active effector protease caspase-1, which then causes cleavage and maturation of proinflammatory cytokines such as pro-interleukin $1 \beta$ (pro-IL$1 \beta$ ) into its active form IL- $1 \beta$ as well as that of IL-18. These trigger a cascade of other downstream mediators of inflammation such as interleukin 6 (IL-6), tumor necrosis factor (TNF), prostaglandins and leukotrienes $(13,14)$. Accordingly, it was also observed that IL-1 $\beta$, among other pro-inflammatory mediators, was produced in SARS-CoV infected ACE2- (viral receptor) expressing epithelial cells, pneumocytes and macrophages of bronchial and pulmonary tissues (15). In agreement with the role of $\mathrm{E}$ protein in triggering pro-inflammatory cytokines, it was also shown that $\mathrm{E}$ protein ion channel activity promote lung inflammation, fluid accumulation and bronchoalveolar epithelial damage. Further confirming this role, studies with a mutant E protein lacking IC activity showed better outcome particularly in terms of reduced edema in tissues $(10,16)$. Moreover, consistent with these findings, it was observed that the HIV-1 virus Vpu channel inhibitor Hexamethylene amiloride (HMA) also hindered coronavirus replication in cultured cells and inhibited the conductance of $\mathrm{E}$ protein ion channels in human coronavirus 229E (HCoV-229E) and mouse hepatitis virus (MHV) (17). Likewise, the ORF3a protein, a potassium $\left(\mathrm{K}^{+}\right)$ion channel viroporin, was shown to render host cell lysosome dysfunctional and cause caspase-1 activation either directly or via increased potassium $\left(\mathrm{K}^{+}\right)$efflux, leading to the NLRP3 inflammasome activation. Furthermore, it caused NFkB-mediated up-regulation of transcription of the pro-IL- $1 \beta$ cytokine gene and pyroptotic cell death $(7,14,18)$ (see Figure 1).
Therefore, it is evident that SARS-CoV encoded viroporins, i.e., E protein and ORF3a activate the NLRP3 inflammasome and assembly. This leads to activation of inflammatory cascade involving cytokines such as IL-1 $\beta$, IL-6, TNF, and other mediators as part of the host inflammatory responses to SARS-CoV infection and contribute to tissue damage.

\section{NLRP3 INFLAMMASOME: A POTENTIAL DRUG TARGET IN COVID-19}

Although, innate immune mechanisms such as optimal activation of the NLRP3 inflammasome plays an important role in antiviral host defenses, its aberrant activation and downstream mediators often lead to pathological tissue injury during infection (19). Also, infection with SARS-CoV is known to induce a storm of pro-inflammatory cytokines, especially IL-1 $\beta$, IL-6, and TNF. These play an important role in the progression of tissue inflammation causing acute respiratory distress syndrome ARDS (10), which is a form of acute lung injury (ALI) and often leads to death. It is noteworthy that ARDS has been the leading cause of death in patients infected with SARS-CoV and MERS-CoV (1). Several studies have reported the important role of NLRP3 inflammasome activation in relation to the pathogenesis of ARDS and ALI (20-22). The pathogenesis of ARDS is driven by these pro-inflammatory cytokines, i.e., IL-1 $\beta$, IL-6, and TNF and other mediators of inflammation. This is manifested by pathological events such as recruitment of inflammatory and phagocytic cells, complement activation, opsonization, increased permeability of endothelial and epithelial cells causing disruption of the air-blood barrier and accumulation of protein-rich fluid in alveoli of lungs, as well as other systemic and hemodynamic effects (23-25). Consistent with this cytokine-mediated immunopathology, elevated levels of IL-1 $\beta$, IL- 6 , and TNF have also been observed in the broncho-alveolar lavage and plasma of ARDS patients (26). Moreover, it has been observed that there is a positive correlation between serum level of these cytokines and mortality rate in ARDS patients (27).

Based on this strong inflammatory potential of the NLRP3 inflammasome in the context of infections caused by SARSCoVs, it appears to be an important druggable target, and its inhibition can potentially reduce tissue inflammation, also in the context of COVID-19. Based on the observed divergence of some SARS-CoV-2 encoded activators of inflammasome (viroporins) from that of SARS-CoV, comparative mechanistic studies of these viral proteins particularly in relation to NLRP3 inflammasome activation are yet to be performed. Nevertheless, cytokine storm is the main cause of inflammation in COVID19 highlighting an important role of NLRP3 inflammasome. Accordingly, high levels of IL-1 $\beta$ and other cytokines have been found in COVID-19 patients (28). Whereas, a variety of drugs such as remdesivir (29), favipiravir (30), glucocorticoids (31), chloroquine (32), hydroxychloroquine plus azithromycin (2) have recently been tested for their potential beneficial effect, however, airway management and ventilatory support (33) remain the mainstay of treatment in critically ill COVID-19 


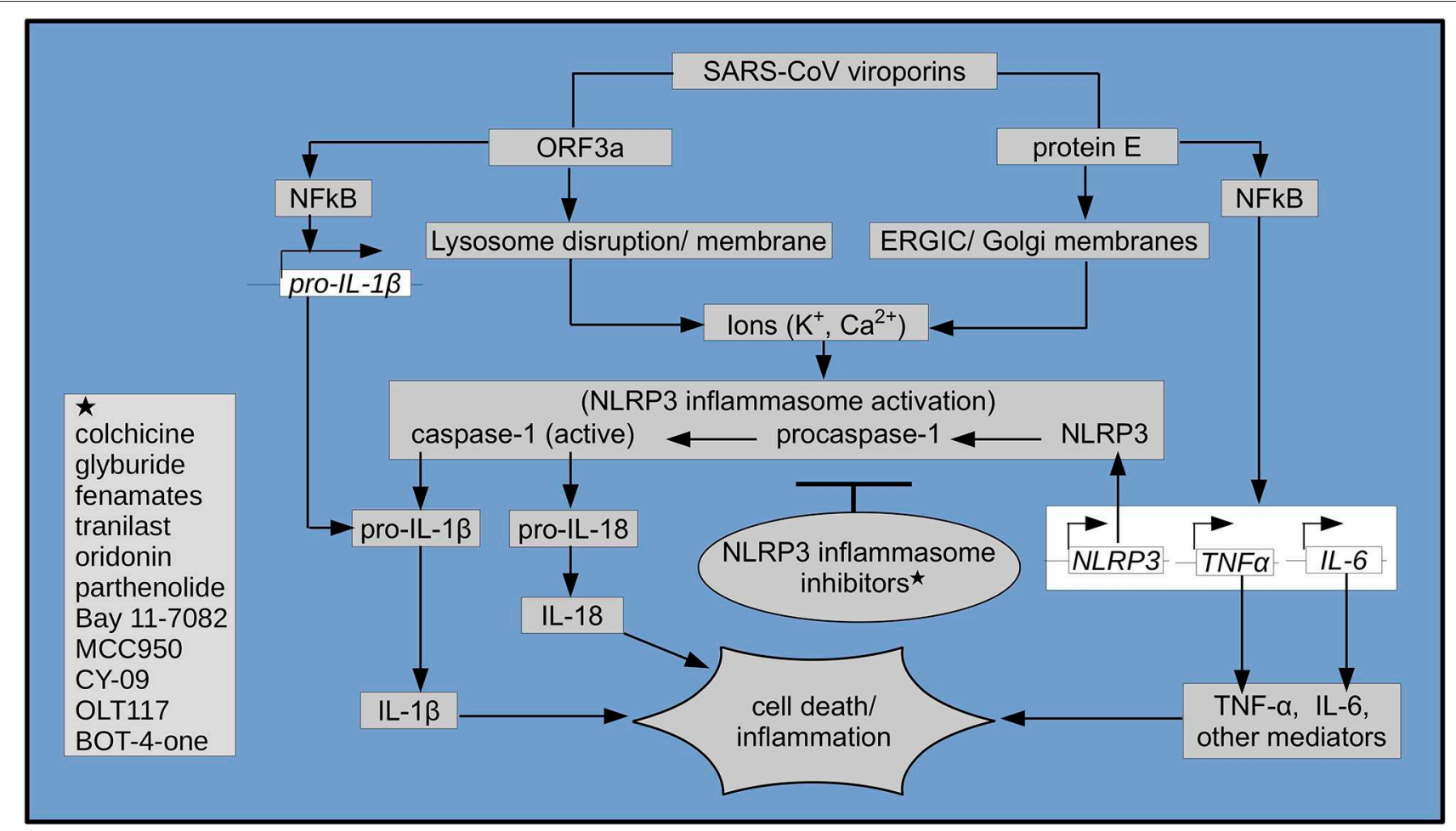

FIGURE 1 | Schematic representation of SARS-CoV viroporin-mediated NLRP3 inflammasome activation, its inhibitors (shown with asterisks) and downstream inflammatory cascades leading to inflammation and cell death. Genes (italicized) in empty boxes, respective proteins in gray boxes.

patients. Given the key role of cytokines in causing inflammation, blocking their effects using biologic agents has revolutionized the treatment of rheumatoid arthritis, psoriasis, inflammatory bowel disease, and other auto-inflammatory diseases (34). Likewise, based on the SARS-CoV-2-induced cytokine-mediated inflammatory response, biologic agents that target cytokines such as the IL-1 receptor antagonist Anakinra, antibody against IL-6 receptor, i.e., Tocilizumab and anti-interferon gamma (IFN- $\gamma$ ) antibody Emapalumab have also been considered in clinical studies. Nevertheless, there is a dire need of effective therapy, novel agents or repurposed drugs, against the novel SARS-CoV-2 (COVID-19) so that to reduce mortality of this disease.

Efforts have been made to find potential inhibitors of the NLRP3 inflammasome, especially in the context of its role in various inflammatory diseases. Luckily, several inhibitors of the NLRP3 inflammasome including natural products as well as approved drugs, have been identified (see Figure 1). Known for their anti-inflammatory properties, natural products such as Oridonin (found in Rabdosia rubescens plant) and Parthenolide (sesquiterpene lactone found in feverfew plant) as well as synthetic compound Bay 11-7082 and related vinyl sulfone compounds have been shown to exert their effects via inhibition of the NLRP3 inflammasome. Interestingly, parthenolide and Bay 11-7082, inhibiting the NLRP3 inflammasome and inflammatory NFkB pathways, were shown to reduce lung inflammation and improve survival in SARS-CoV-infected animals $(9,35,36)$.
Likewise, a sulfonylurea drug Glyburide which is widely used for the treatment of Diabetes type 2, was also shown to inhibit the NLRP3 inflammasome. Primarily acting by blocking the ATP-sensitive $\mathrm{K}^{+}$channels $\left(\mathrm{K}_{\mathrm{ATP}}\right)$ in $\beta$-cells of the pancreas, Glyburide was shown to act upstream and prevent NLRP3 inflammasome activation. Interestingly, Glyburide-mediated inhibition of $\mathrm{K}^{+}$efflux was shown to inhibit NLRP3 and secretion of IL-1 $\beta$ in cells infected with RNA viruses, i.e., vesicular stomatitis virus (VSV) and encephalomyocarditis virus (EMCV) (19, 37). Similarly, Tranilast, a drug used for the treatment of allergic conditions such as bronchial asthma, was shown to inhibit the NFkB pathway, several cytokines as well as the NLRP3 oligomerization, thereby preventing the inflammasome assembly. Based on these effects, Tranilast showed significant beneficial effects in animals models of NLRP3 inflammasomerelated diseases of humans (38).

More importantly, an alkaloid drug Colchicine which is known for its effects such as tubulin disruption, alteration of E-selectin distribution on endothelial surfaces, inducing loss of adhesion molecule L-selectins and preventing adhesion and recruitment of neutrophil, has also been shown to inhibit activation of the NLRP3 inflammasome. Subsequently, this led to blocking of the pro-inflammatory IL-1 $\beta$ and IL-18 cytokine production $(39,40)$. Colchicin is frequently used for auto-inflammatory conditions such as gouty arthritis (41) and familial mediterranean fever (FMF) $(42,43)$. However, its antiinflammatory role due to inhibition of the NLRP3 inflammasome activation, has also been shown in other conditions such as acute 
coronary syndrome (ACS) (44), oxidized low-density lipoprotein (oxLDL) and cholesterol crystal-induced macrophage activation (45) and non-steroidal anti-inflammatory drugs- (NSAIDs) induced small intestinal injury (46).

NSAIDs is a group of anti-inflammatory drugs, inhibiting cyclooxygenase (COX) enzymes in the synthesis of prostaglandins and other mediators, and widely used for the treatment of pain and inflammation. Studies have shown that, unlike other NSAIDs, fenamates (mefenamic acid, flufenamic acid) selectively inhibit the NLRP3 inflammasome and IL-1 $\beta$ release via inhibiting the membrane volumeregulated anion $\left(\mathrm{Cl}^{-}\right)$channel (VRAC), independent of its cyclooxygenase-1 (COX-1) mediated anti-inflammatory activity (47). In agreement with these findings, fenamates (mefenamic acid and meclofenamic acid) were observed to have considerable activity against viral replication, and a combination of ribavirin together with mefenamic acid was shown to be effective in reducing viral yield in cells infected with a positive-sense RNA genome chikungunya virus (48). Several other compounds such as MCC950 (49), CY-09 (50), OLT117 (51), and a benzoxathiole derivative BOT-4-one (52) have been shown to inhibit the NLRP3 inflammasome

\section{REFERENCES}

1. Zaki AM, Van Boheemen S, Bestebroer TM, Osterhaus ADME, Fouchier RAM. Isolation of a novel coronavirus from a man with pneumonia in Saudi Arabia. N Engl J Med. (2012) 367:1814-20. doi: 10.1056/NEJMoa1211721

2. Gautret P, Lagier JC, Parola P, Hoang VT, Meddeb L, Mailhe L, et al. Hydroxychloroquine and azithromycin as a treatment of COVID-19: results of an open-label non-randomized clinical trial. Int J Antimicrob Agents. (2020) 105949. doi: 10.1016/j.ijantimicag.2020.105949. [Epub ahead of print].

3. Tan YJ, Lim SG, Hong W. Characterization of viral proteins encoded by the SARS-coronavirus genome. Antiviral Res. (2005) 65:69-78. doi: 10.1016/j.antiviral.2004.10.001

4. Torres J, Maheswari U, Parthasarathy K, Ng L, Liu DX, Gong X. Conductance and amantadine binding of a pore formed by a lysine-flanked transmembrane domain of SARS coronavirus envelope protein. Protein Sci. (2007) 16:206571. doi: $10.1110 /$ ps.062730007

5. Letko M, Marzi A, Munster V. Functional assessment of cell entry and receptor usage for SARS-CoV-2 and other lineage B betacoronaviruses. Nat Microbiol. (2020) 5:562-9. doi: 10.1038/s41564-020-0688-y

6. Nieva JL, Madan V, Carrasco L. Viroporins: structure and biological functions. Nat Rev Microbiol. (2012) 10:563-74. doi: 10.1038/nrmicro2820

7. Siu KL, Yuen KS, Castano-Rodriguez C, Ye ZW, Yeung ML, Fung SY, et al. Severe acute respiratory syndrome Coronavirus ORF3a protein activates the NLRP3 inflammasome by promoting TRAF3-dependent ubiquitination of ASC. FASEB J. (2019) 33:8865-77. doi: 10.1096/fj.201802418R

8. Castaño-Rodriguez C, Honrubia JM, Gutiérrez-Álvarez J, DeDiego ML, Nieto-Torres JL, Jimenez-Guardeno JM, et al. Role of severe acute respiratory syndrome coronavirus viroporins $\mathrm{E}, 3 \mathrm{a}$, and $8 \mathrm{a}$ in replication and pathogenesis. MBio. (2018) 9:e02325-17. doi: 10.1128/mBio.02325-17

9. DeDiego ML, Nieto-Torres JL, Regla-Nava JA, Jimenez-Guardeno JM, Fernandez-Delgado R, Fett C, et al. Inhibition of NF-kB-mediated inflammation in severe acute respiratory syndrome coronavirus-infected mice increases survival. J Virol. (2014) 88:913-24. doi: 10.1128/JVI.02576-13

10. Nieto-Torres JL, Verdiá-Báguena C, Jimenez-Guardeño JM, ReglaNava JA, Castano-Rodriguez C, Fernandez-Delgado R, et al. Severe acute respiratory syndrome coronavirus $\mathrm{E}$ protein transports calcium ions and activates the NLRP3 inflammasome. Virology. (2015) 485:330-9. doi: 10.1016/j.virol.2015.08.010 and have been discussed in relation to NLRP3-associated inflammatory diseases.

To summarize, this manuscript underlines the crucial role of NLRP3 inflammasome activation in the pathogenesis of diseases caused by SARS-CoVs, discusses reported inhibitors of the NLRP3 inflammasome in the context of inflammatory diseases and draws attention toward potential role of these (and similar agents) inhibitors in the treatment of SARS-CoV-2 (COVID-19). To this end, the evaluation of these reported (and other similar known or novel agents) inhibitors of the NLRP3 inflammasome in pre-clinical and/or clinical studies might offer new alternatives, especially in the form of potential repurposing of approved drugs for the treatment of COVID-19. Furthermore, considering the clinical use of several NLRP3 inhibitor drugs for the treatment of other inflammatory diseases, controlled studies of these comorbid patients might also determine potential usefulness of these agents in the treatment of COVID-19.

\section{AUTHOR CONTRIBUTIONS}

AS conceived the idea, surveyed literature, and wrote the manuscript.

11. Elliott EI, Sutterwala FS. Initiation and perpetuation of NLRP3 inflammasome activation and assembly. Immunol Rev. (2015) 265:35-52. doi: 10.1111/imr.12286

12. Latz E, Xiao TS Stutz A. Activation and regulation of the inflammasomes. Nat Rev Immunol. (2013) 13:397-411. doi: 10.1038/nri3452

13. Mangan MSJ, Olhava EJ, Roush WR, Seidel HM, Glick GD, Latz E. Targeting the NLRP3 inflammasome in inflammatory diseases. Nat Rev Drug Discov. (2018) 17:588-606. doi: 10.1038/nrd.2018.97

14. Yue Y, Nabar NR, Shi CS, Kanenyeva O, Xiao X, Hwang IY, et al. SARScoronavirus open reading frame-3a drives multimodal necrotic cell death. Cell Death Dis. (2018) 9:904. doi: 10.1038/s41419-018-0917-y

15. He L, Ding Y, Zhang Q, Chen X, He Y, Shen H, et al. Expression of elevated levels of pro-inflammatory cytokines in SARS-CoV-infected ACE2+ cells in SARS patients: relation to the acute lung injury and pathogenesis of SARS. $J$ Pathol. (2006) 210:288-97. doi: 10.1002/path.2067

16. Nieto-Torres JL, DeDiego ML, Verdiá-Báguena C, Jimenez-Guardeno JM, Regla-Nava JA, Fernandez-Delgado R, et al. Severe acute respiratory syndrome coronavirus envelope protein ion channel activity promotes virus fitness and pathogenesis. PLoS Pathog. (2014) 10:e1004077. doi: 10.1371/journal.ppat.1004077

17. Wilson L, Gage P, Ewart G. Hexamethylene amiloride blocks E protein ion channels and inhibits coronavirus replication. Virology. (2006) 353:294306. doi: 10.1016/j.virol.2006.05.028

18. Chen IY, Moriyama M, Chang MF, Ichinohe T. Severe acute respiratory syndrome coronavirus viroporin 3a activates the NLRP3 inflammasome. Front Microbiol. (2019) 10:1-9. doi: 10.3389/fmicb.2019.00050

19. Costa LS, Outlioua A, Anginot A, Akarid K, Arnoult D. RNA viruses promote activation of the NLRP3 inflammasome through cytopathogenic effect-induced potassium efflux. Cell Death Dis. (2019) 10:346. doi: 10.1038/s41419-019-1579-0

20. Jones HD, Crother TR, Gonzalez-Villalobos RA, Jupelli M, Chen S, Dagvadorj J, et al. The NLRP3 inflammasome is required for the development of hypoxemia in LPS/mechanical ventilation acute lung injury. Am J Respir Cell Mol Biol. (2014) 50:270-80. doi: 10.1165/rcmb.2013-0087OC

21. Li D, Ren W, Jiang Z, Zhu L. Regulation of the NLRP3 inflammasome and macrophage pyroptosis by the p38 MAPK signaling pathway in a mouse model of acute lung injury. Mol Med Rep. (2018) 18:4399409. doi: $10.3892 / \mathrm{mmr} .2018 .9427$ 
22. Grailer JJ, Canning BA, Kalbitz M, Haggadone MD, Dhond RM, Andjelkovic $\mathrm{AV}$, et al. Critical Role for the NLRP3 Inflammasome during acute lung injury. J Immunol. (2014) 192:5974-83. doi: 10.4049/jimmunol.1400368

23. Mathay MA, Zemans RL. The acute respiratory distress syndrome: pathogenesis and treatment. Annu Rev Pathol. (2011) 6:14763. doi: 10.1146/annurev-pathol-011110-130158

24. DElia RV, Harrison K, Oyston PC, Lukaszewski RA, Clark GC. Targeting the "cytokine storm" for therapeutic benefit. Clin Vaccine Immunol. (2013) 20:319-27. doi: 10.1128/CVI.00636-12

25. Huppert LA, Mathay MA, Ware LB. Pathogenesis of acute respiratory distress syndrome. Semin Respir Crit Care Med. (2019) 40:31-9. doi: 10.1055/s-0039-1683996

26. Han S, Mallampalli RK. The acute respiratory distress syndrome: from mechanism to translation. J Immunol. (2015) 194:85560. doi: 10.4049/jimmunol.1402513

27. Parsons PE, Eisner MD, Thompson BT, Mathay MA, Ancukiewicz M, Bernard $\mathrm{GR}$, et al. Lower tidal volume ventilation and plasma cytokine markers of inflammation in patients with acute lung injury. Crit Care Med. (2005) 33:1-6. doi: 10.1097/01.CCM.0000149854.61192.DC

28. Huang C, Wang Y, Li X, Ren L, Zhao J, Hu Y. Clinical features of patients infected with 2019 novel coronavirus in Wuhan, China. Lancet. (2020) 395:497-506. doi: 10.1016/S0140-6736(20)30183-5

29. Wang M, Cao R, Zhang L, Yang X, Liu J, Xu M, et al. Remdesivir and chloroquine effectively inhibit the recently emerged novel coronavirus (2019$\mathrm{nCoV}$ ) in vitro. Cell Res. (2020) 30:269-71. doi: 10.1038/s41422-020-0282-0

30. Cai Q, Yang M, Liu D, Chen J, Shu D, Xia J, et al. Experimental treatment with favipiravir for COVID-19: an open-label control study. Engineering. (2020). doi: 10.1016/j.eng.2020.03.007. [Epub ahead of print].

31. Wu C, Chen X, Cai Y, Xia J, Zhou X, Xu S, et al. Risk factors associated with acute respiratory distress syndrome and death in patients with coronavirus disease 2019 pneumonia in Wuhan, China. JAMA Intern Med. (2020) e200994. doi: 10.1001/jamainternmed.2020.0994. [Epub ahead of print].

32. Gao J, Tian Z, Yang Xu. Breakthrough: chloroquine phosphate has shown apparent efficacy in treatment of COVID-19 associated pneumonia in clinical studies. Biosci Trends. (2020) 14:72-3. doi: 10.5582/bst.2020.01047

33. Jin YH, Cai L, Cheng ZS, Cheng H, Deng T, Fan YP, et al. A rapid advice guideline for the diagnosis and treatment of 2019 novel coronavirus (2019nCoV) infected pneumonia (standard version). Mil Med Res. (2020) 7:1-23. doi: 10.1186/s40779-020-0233-6

34. Her M, Kavanaugh A. Alterations in immune function with biologic therapies for autoimmune disease. J Allergy Clin Immunol. (2016) 137:1927. doi: 10.1016/j.jaci.2015.10.023

35. He H, Jiang H, Chen Y, Ye J, Wang A, Wang C, et al. Oridonin is a covalent NLRP3 inhibitor with strong anti-inflammasome activity. Nat Commun. (2018) 9:2550. doi: 10.1038/s41467-018-04947-6

36. Juliana C, Fernandes-Alnemri T, Wu J, Datta P, Solorzano L, Yu JW, et al. Anti-inflammatory compounds parthenolide and bay 11-7082 are direct inhibitors of the inflammasome. J Biol Chem. (2010) 285:9792802. doi: 10.1074/jbc.M109.082305

37. Lamkanfi M, Mueller JL, Vitari AC, Misaghi S, Fedorova A, Deshayes K, et al. Glyburide inhibits the Cryopyrin/Nalp3 inflammasome. J Cell Biol. (2009) 187:61-70. doi: 10.1083/jcb.200903124

38. Huang Y, Jiang H, Chen Y, Wang X, Yang Y, Tao J, et al. Tranilast directly targets NLRP 3 to treat inflammasome-driven diseases. EMBO Mol Med. (2018) 10:e8689. doi: 10.15252/emmm.201708689

39. Leung YY, Yao Hui LL, Kraus VB. Colchicine - update on mechanisms of action and therapeutic uses. Semin Arthritis Rheum. (2015) 45:34150. doi: 10.1016/j.semarthrit.2015.06.013

40. Misawa T, Takahama M, Kozaki T, Lee H, Zou J, Saitoh T, et al. Microtubuledriven spatial arrangement of mitochondria promotes activation of the NLRP3 inflammasome. Nat Immunol. (2013) 14:454-60. doi: 10.1038/ni.2550
41. Martinon F, Pétrilli V, Mayor A, Tardivel A, Tschopp J. Gout-associated uric acid crystals activate the NALP3 inflammasome. Nature. (2006) 440:23741. doi: $10.1038 /$ nature 04516

42. Gorp HV, Saavedra PHV, De Vasconcelos NM, Van Opdenbosch N, Vande Walle L, Matusiak M, et al. Familial Mediterranean fever mutations lift the obligatory requirement for microtubules in Pyrin inflammasome activation. Proc Natl Acad Sci USA. (2016) 113:14384-9. doi: 10.1073/pnas.1613 156113

43. Park YH, Wood G, Kastner DL, Chae JJ. Pyrin inflammasome activation and RhoA signaling in the autoinflammatory diseases FMF and HIDS. Nat Immunol. (2016) 17:914-21. doi: 10.1038/ni.3457

44. Robertson S, Martínez GJ, Payet CA, Barraclough JY, Celermajer DS, Bursill C, et al. Colchicine therapy in acute coronary syndrome patients acts on caspase1 to suppress NLRP3 inflammasome monocyte activation. Clin Sci. (2016) 130:1237-46. doi: 10.1042/CS20160090

45. Fernando S, Schwarz N, Williamson A, Toledo D, Zareh J, Di Dartolo B, et al. Anti-inflammatory effects of colchicine on oxidised low-density lipoproteins and cholesterol crystal-induced macrophage activation in vitro. Heart Lung Circul. (2017) 26:S69-70. doi: 10.1016/j.hlc.2017.06.060

46. Otani K, Watanabe T, Shimada S, Takeda S, Itani S, Higashimori $A$, et al. Colchicine prevents NSAID-induced small intestinal injury by inhibiting activation of the NLRP3 inflammasome. Sci Rep. (2016) 6:32587. doi: $10.1038 /$ srep32587

47. Daniels MJ, Rivers-Auty J, Schilling T, Spencer NG, Watremez W, Fasolino V, et al. Fenamate NSAIDs inhibit the NLRP3 inflammasome and protect against Alzheimer's disease in rodent models. Nat Commun. (2016) 7:12504. doi: $10.1038 /$ ncomms 12504

48. Rothan HA, Bahrani H, Abdulrahman AY, Mohamed Z, Teoh TC, Othman S, et al. Mefenamic acid in combination with ribavirin shows significant effects in reducing chikungunya virus infection in vitro and in vivo. Antiviral Res. (2016) 127:50-6. doi: 10.1016/j.antiviral.2016.01.006

49. Coll RC, Robertson AA, Chae JJ, Higgins SC, Munoz-Planillo $\mathrm{R}$, Inserra $\mathrm{MC}$, et al. A small molecule inhibitior of the NLRP3 inflammasome for the treatment of inflammatory diseases. Nat Med. (2015) 21:248-55. doi: 10.1038/n m.3806

50. Jiang $\mathrm{H}, \mathrm{He} \mathrm{H}$, Chen $\mathrm{Y}$, Huang $\mathrm{W}$, Cheng J, Ye J, et al. Identification of a selective and direct NLRP3 inhibitor to treat inflammatory disorders. J Exp Med. (2017) 214:3219-38. doi: 10.1084/jem.201 71419

51. Marchetti C, Swartzwelter B, Koenders MI, Azam T, Tengesdal IW, Powers N, et al. NLRP3 inflammasome inhibitor OLT1177 suppresses joint inflammation in murine models of acute arthritis. Arthritis Res Ther. (2018) 20:169. doi: 10.1186/s13075-0181664-2

52. Shim DW, Shin WY, Yu SH, Kim BH, Ye SK, Koppula S, et al. BOT-4-one attenuates NLRP3 inflammasome activation: NLRP3 alkylation leading to the regulation of its ATPase activity and ubiquitination. Sci Rep. (2017) 7:15020. doi: 10.1038/s41598-017-1 5314-8

Conflict of Interest: The author declares that the research was conducted in the absence of any commercial or financial relationships that could be construed as a potential conflict of interest.

Copyright (c) 2020 Shah. This is an open-access article distributed under the terms of the Creative Commons Attribution License (CC BY). The use, distribution or reproduction in other forums is permitted, provided the original author(s) and the copyright owner(s) are credited and that the original publication in this journal is cited, in accordance with accepted academic practice. No use, distribution or reproduction is permitted which does not comply with these terms. 